\title{
The protein that binds the 3 ' end of histone mRNA: a novel RNA-binding protein required for histone pre-mRNA processing
}

\author{
Zeng-Feng Wang, ${ }^{1,3}$ Michael L. Whitfield, ${ }^{1,2}$ Thomas C. Ingledue III, ${ }^{1,2}$ Zbigniew Dominski, $^{1,2}$ and \\ William F. Marzluff ${ }^{1-4}$ \\ ${ }^{1}$ Program in Molecular Biology and Biotechnology, ${ }^{2}$ Department of Biochemistry and Biophysics, and ${ }^{3}$ Department of \\ Biology, University of North Carolina at Chapel Hill, Chapel Hill, North Carolina 27599 USA
}

\begin{abstract}
Replication-dependent histone mRNAs are not polyadenylated but end in a conserved 26-nucleotide structure that contains a stem-loop. Much of the cell cycle regulation of histone mRNA is post-transcriptional and is mediated by the 3' end of histone mRNA. The stem-loop binding protein (SLBP) that binds the 3' end of histone mRNA is a candidate for the factor that participates in most, if not all, of the post-transcriptional regulatory events. We have cloned the cDNA for the SLBP from humans, mice, and frogs, using the recently developed yeast three-hybrid system. The human SLBP is a 31-kD protein and contains a novel RNA-binding domain, which has been mapped to a 73-amino-acid region of the protein. The cloned SLBP is the protein bound to the $3^{\prime}$ end of histone mRNA as antibodies specific for the SLBP remove all specific binding activity from nuclear and polyribosomal extracts. These depleted extracts do not cleave histone pre-mRNA efficiently, demonstrating that the SLBP is required for efficient histone pre-mRNA processing.
\end{abstract}

[Key Words: Histone mRNA; $3^{\prime}$ end; stem-loop binding protein; pre-mRNA processing]

Received August 30, 1996; revised version accepted October 21, 1996.

Metazoan replication-dependent histone mRNAs are the only cellular mRNAs that do not have poly(A) tails, ending instead in a highly conserved stem-loop. Because the replication-dependent histone genes do not have introns, the only processing reaction required for the formation of mature histone mRNA is cleavage to form the $3^{\prime}$ end. Processing of the $3^{\prime}$ end of histone mRNA requires two cis elements, the stem-loop that interacts with a factor termed the hairpin binding factor (HBF) (Mowry and Steitz 1987a; Vasserot et al. 1989; Melin et al. 1992), and a purine-rich sequence located 9-14 nucleotides $3^{\prime}$ of the stem-loop that binds the U7 small nuclear ribonucleoprotein particle (snRNP) (Mowry and Steitz 1987b; Cotten et al. 1988; Soldati and Schümperli 1988; Bond et al. 1991). In addition to these two trans-acting factors, there is a heat-labile factor that has not been well characterized (Gick et al. 1987).

The expression of the replication-dependent histone mRNAs is tightly coupled with DNA replication, with significant amounts of histone mRNA present only in $S$ phase. The concentrations of histone mRNA are regulated at both transcriptional and post-transcriptional steps (Schümperli 1986; Marzluff and Pandey 1988;

${ }^{4}$ Corresponding author.
Heintz 1991). The post-transcriptional regulation is directed by the $3^{\prime}$ end of the histone mRNA /Stauber et al. 1986), presumably through interactions with trans-acting factors. There is regulation at two post-transcriptional steps, processing of the $3^{\prime}$ end of histone mRNA in the nucleus as cells progress from $G_{1}$ to $S$ phase /Gick et al. 1987; Stauber and Schümperli 1988; Harris et al. 1991) and rapid degradation of the histone mRNA in the cytoplasm as cells progress from the end of $\mathrm{S}$ phase to mitosis (Pandey and Marzluff 1987; Harris et al. 1991).

Previously, we have described a protein, termed the stem-loop binding protein (SLBP), that is bound to the $3^{\prime}$ end of histone mRNA in polyribosomes (Hanson et al. 1996). The SLBP is also present in the nucleus and has been implicated in the $3^{\prime}$ processing of histone mRNA, either as HBF or as a component of HBF (Dominski et al. 1995). Thus, the SLBP is an example of a protein that may shuttle between the nucleus and the cytoplasm. Using a yeast three-hybrid selection system for RNA-binding proteins (SenGupta et al. 1996), we have cloned the cDNA for the SLBP from humans and frogs. The mammalian SLBP is a $31-\mathrm{kD}$ protein that is not related to other proteins in the data base and that contains a novel 73-amino-acid RNA-binding domain. Using antibodies specific for the cloned SLBP we show it is the major protein that binds the $3^{\prime}$ end of histone mRNA in both 
the nucleus and the cytoplasm and that it is required for histone pre-mRNA processing.

\section{Results}

The stem-loop at the $3^{\prime}$ end of the histone mRNA is necessary for efficient $3^{\prime}$ end formation in vivo (Pandey et al. 1994) and is necessary and sufficient for regulation of histone mRNA degradation (Pandey and Marzluff 1987). We have detected a specific protein, termed SLBP, that interacts with the $3^{\prime}$ end of histone mRNA. The SLBP is present in both nuclei and polyribosomes (Pandey et al. 1991; Williams and Marzluff 1995; Hanson et al. 1996), with most of the SLBP present in polyribosomes, presumably as part of the histone mRNP (Hanson et al. 1996). The SLBP binds the stem-loop as a monomer (Hanson et al. 1996), requiring the 26 nucleotides at the 3 ' end of histone mRNA for efficient binding (Williams and Marzluff 1995). The SLBP-RNA complex is extremely stable, suggesting that the SLBP interacts with the histone pre-mRNA and then remains bound for the lifetime of the histone mRNA (Williams and Marzluff 1995). Partly because of the low abundance of the SLBP, purification of sufficient SLBP for cloning the SLBP cDNA has not yet been possible (Hanson et al. 1996).

\section{Cloning of the SLBP}

Marv Wickens, Stan Fields, and coworkers have recently devised a three-hybrid screen, a variation of the yeast two-hybrid technology, for selecting RNA-binding proteins in yeast (SenGupta et al. 1996). Briefly, a vector expressing the lexA DNA-binding domain fused with the phage MS-2 protein was integrated into the yeast genome. A vector expressing a hybrid RNA from the
RNase P promoter was introduced into the yeast. This hybrid RNA contains the MS-2 protein-binding site and the target RNA sequence of interest, in this case the histone stem-loop. Finally, a library containing cDNAs fused to the Gal4 activation domain is introduced. Expression of a fusion protein that interacts with the target RNA sequence will result in activation of transcription from promoters that bind the lexA-MS2 fusion protein (Fig. 1A). The SLBP is an excellent candidate for using this technology to select a specific RNA-binding protein, as the histone $3^{\prime}$ stem-loop is present only in metazoans, the SLBP binds to the stem-loop as a monomer (Hanson et al. 1996), and the complex is very stable (Williams and Marzluff 1995).

A diagram of the strategy, adapted from Wickens and coworkers (SenGupta et al. 1996), is shown in Figure 1A. Two genes, his 3 conferring resistance to aminotriazole and lac $Z$ encoding $\beta$-galactosidase, which will turn the colonies blue in the presence of X-Gal, will be activated by the Gal4 activation domain fused with a cDNA that binds specifically to the RNA "bait." The conserved 26nucleotide sequence present at the $3^{\prime}$ end of all metazoan histone mRNAs is shown in Figure 1B. The structure of the RNA bait is shown in Figure 1C. We placed the histone stem-loop at the $3^{\prime}$ end of the bait RNA, the position where it is found in mature histone mRNA, by terminating transcription from the RNase P promoter by RNA polymerase III with a run of 6 Ts after the ACCCA at the $3^{\prime}$ end of the stem-loop bait. The sequence of the loop we used was UCUC, chosen to avoid a potential run of 4 Us in the RNA that might have served as a transcription termination site for RNA polymerase III. A C at position 2 in the loop is present in some mammalian histone mRNAs (Taylor et al. 1986). As a secondary screen for potential clones encoding proteins that inter-
A

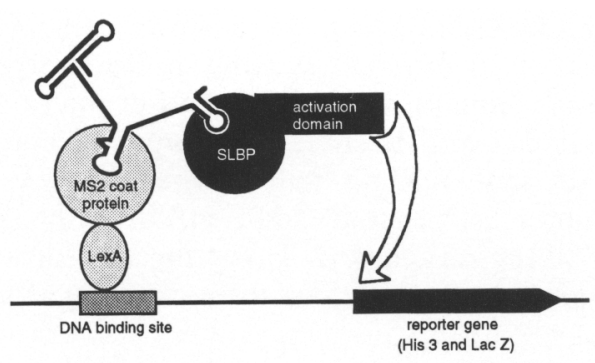

B

C

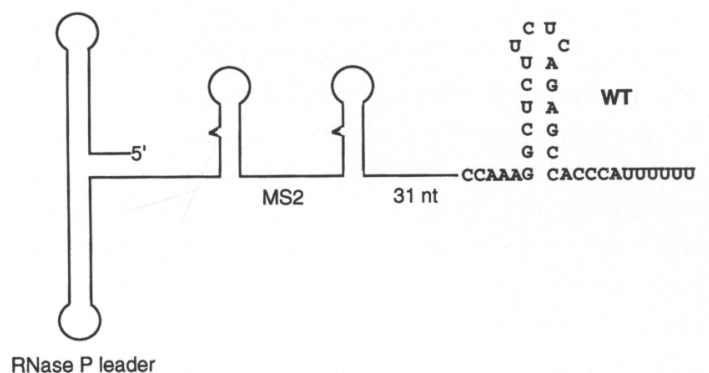

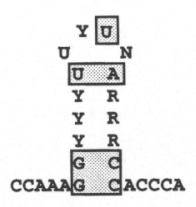

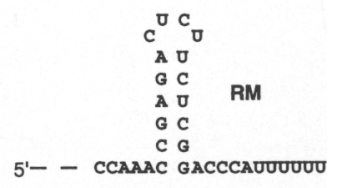

5 - - cCAAAC gaccCAUUUUUU
Figure 1. Strategy for selection of clones containing the RNA-binding activity of the SLBP. $(A)$ The yeast three-hybrid system. A diagram of the strategy for the yeast threehybrid system adapted from Wickens and co-workers is shown (SenGupta et al. 1996). The lexA-MS-2 fusion protein binds to the MS2 RNA-binding site in the RNA and the Gal4-cDNA fusion binds to the target RNA resulting in activation of both the $l a c Z$ and his3 gene in the yeast. $(B)$ The structure of the conserved histone mRNA 3' end. The conserved sequence at the $3^{\prime}$ end of metazoan histone mRNAs is shown. The boxed nucleotides are the invariant nucleotides. (C) Structure of the "bait" RNA and mutant "bait" RNA. The two bait RNAs used in these experiments are shown. The histone stem-loop was placed at the $3^{\prime}$ end of the wild-type (WT) bait RNA and the same sequence reversed was placed at the $3^{\prime}$ end of the mutant (RM) bait. 
act specifically with this sequence, a mutant bait identical with the first one, except with the stem-loop sequence reversed, was constructed (Fig. 1C). This sequence does not bind the SLBP (Williams and Marzluff 1995).

Libraries containing cDNA from HeLa cells and Xenopus oocytes fused with the Gal-4 activation domain were transfected into yeast, and aminotriazole-resistant colonies were selected. Nineteen aminotriazole-resistant colonies were obtained from $2 \times 10^{6}$ transformants from HeLa cell cDNA. These colonies were then plated on indicator plates and the six blue colonies selected (Fig. 2A). Plasmid DNA was prepared from each blue colony, rescued by transformation into Escherichia coli and the plasmid DNA was introduced into the yeast strain containing the reverse-stem bait RNA. Of the six blue colonies, five did not activate the lacZ gene when the mutant stem-loop was used as a bait (Fig. 2B). These five plasmids were independent clones of the same cDNA. Eighteen aminotriazole-resistant colonies were obtained from $2 \times 10^{6}$ transformants from Xenopus cDNA. Ten of these also activated the $l a c Z$ gene. Seven of the ten did not activate the $l a c Z$ gene in the yeast strain containing the mutant stem-loop. These seven plasmids were independent clones of the same cDNA. The plasmids that gave blue colonies in the yeast strain containing the mutant stem-loop probably expressed a fusion protein that bound either to the MS2 protein, to a region of the RNA

A

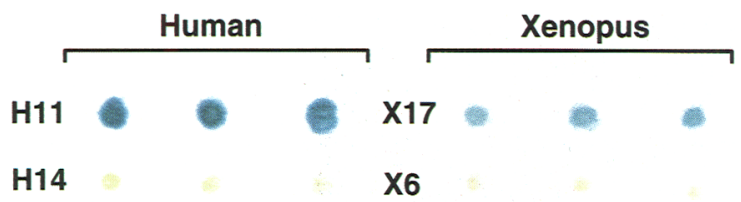

B

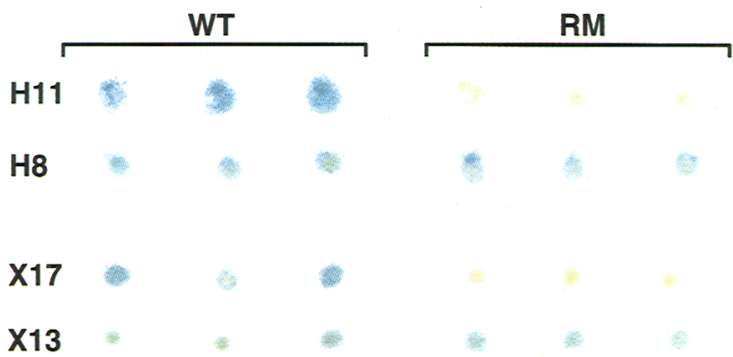

Figure 2. Selection of yeast containing the human SLBP. $|A|$ Representative yeast colonies selected for resistance to $5 \mathrm{~mm}$ aminotriazole were tested for their ability to activate $\beta$-galactosidase specifically through the wild-type histone $3^{\prime}$ end. The aminotriazole-resistant colonies were first tested for expression of $\beta$-galactosidase (top). (B) The plasmid DNA was isolated from the blue colonies $(\mathrm{H} 11, \mathrm{H} 8, \mathrm{X} 17, \mathrm{X} 13)$ and reintroduced into yeast strains containing the wild-type stem-loop (WT) or the mutant (RM) stem-loop sequence. Those plasmids (H11, X17) that gave blue colonies when they were introduced into the yeast carrying the WT stem-loop and white colonies when introduced into yeast containing the mutant RM stem-loop encoded the SLBP. bait that did not include the stem-loop, or directly to the DNA. These clones have not been characterized further.

One of the human cDNA clones contained a $1.7-\mathrm{kb}$ insert starting $5^{\prime}$ of the initiator ATG and ending in a poly(A) tail (Fig. 3A). Comparison of this sequence with the data base revealed that the complete human cDNA was included in overlapping cosmids $\mathrm{HDAB}, \mathrm{HDAC}$, and DHAD from human chromosome 4p16.3 (McCombie et al. 1992). This region, spanning $20 \mathrm{~kb}$, containing eight exons, had been sequenced as part of the search for the Huntington's disease gene (McCombie et al. 1992). The exon-intron boundaries are indicated in Figure 3A. Additional cDNA clones were isolated by screening a phage library, and six phage were isolated that encoded the same mRNA, but none extended further than the largest insert from the yeast screen. The complete human SLBP contains 269 amino acids (Fig. 3A) with a predicted molecular mass of $31 \mathrm{kD}$, significantly smaller than the 45 $\mathrm{kD}$ estimated for the SLBP by SDS-gel electrophoresis (Pandey et al. 1991; Hanson et al. 1996). The reason for this discrepancy is discussed below.

We also cloned the mouse SLBP by screening a phage cDNA library with the human SLBP insert. Five phage were obtained, all encoding different parts of the same cDNA. The longest insert, $1.6 \mathrm{~kb}$, contained a near fulllength cDNA clone. The 5 ' ends of the human gene and the mouse and human cDNAs are compared in Figure 3B. Many of the human clones isolated in the yeast three-hybrid screen were cloned upstream of the methionine that we designated as the initiator methionine, adding additional amino acids from translation of the $5^{\prime}$ untranslated region of the human SLBP mRNA to the fusion protein. Inspection of the human genomic sequence reveals a stop codon in the same frame as the proposed initiator methionine, just $5^{\prime}$ of the longest cDNA clone obtained. In addition there is a candidate for a TATAA box 35 nucleotides from the start of the longest human cDNA clone. Comparison of the $5^{\prime}$ end of the mouse and human SLBP sequences shows that the two sequences are quite different starting immediately $5^{\prime}$ of the ATG, with numerous substitutions and potential insertions and deletions. There is also a stop codon in the 5' UTR in the same reading frame as the proposed initiator methionine of the mouse SLBP mRNA only $39 \mathrm{nu}-$ cleotides $5^{\prime}$ of the ATG codon. Taken together these observations identify this ATG as the start codon for the SLBP.

All the frog clones that specifically bound the stemloop encoded the same polypeptide, and this is clearly the homolog of the human SLBP. Again there were fusion proteins identified in the yeast that included some amino acids from the 5' UTR in some of the frog clones (not shown). The sequences of the human, mouse, and frog SLBP proteins are compared in Figure 3C. The human and mouse cDNAs encode proteins with $89 \%$ identity $(94 \%$ similarity), with the mouse SLBP containing 274 amino acids, attributable to a 5-amino-acid insertion near the carboxyl terminus. The frog SLBP is 253 amino acids long and is $64 \%$ identical ( $82 \%$ similar) with the mouse and $60 \%$ identical ( $78 \%$ similar) with the human 


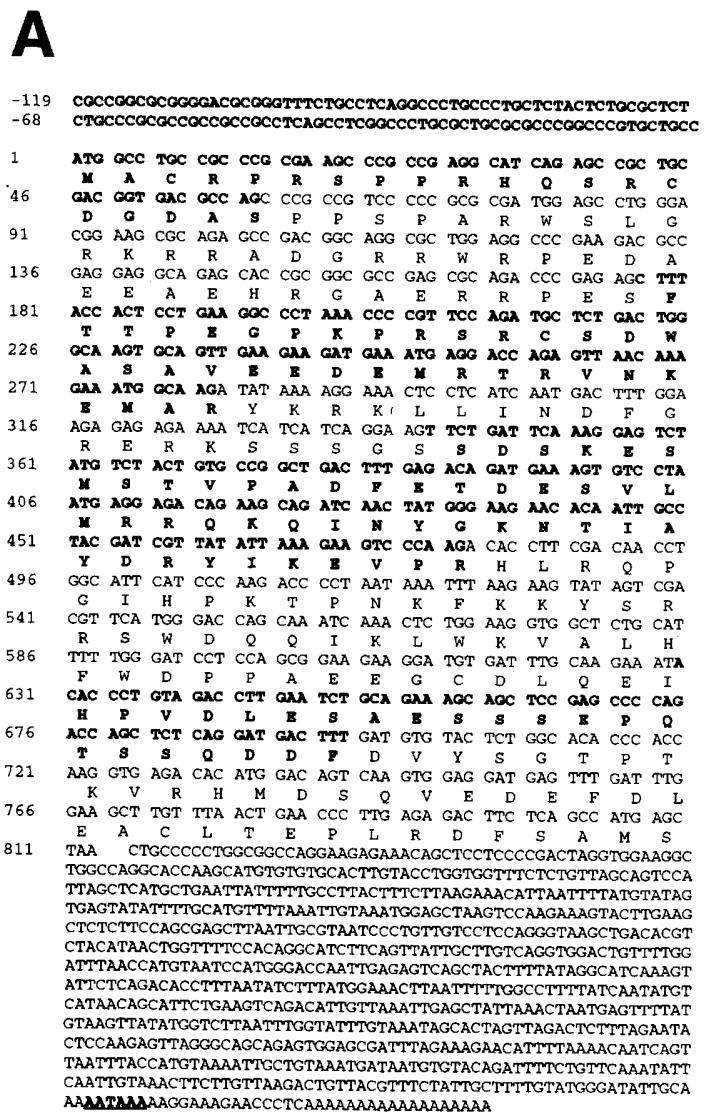

Figure 3. Sequence of the human, mouse, and frog SLBPs. (A) The sequence of the longest human SLBP cDNA is shown, together with the predicted amino acid sequence of the human SLBP. Exons are shown by alternating bold and normal print. The polyadenylation signal is shown in bold and underlined. $(B)$ The $5^{\prime}$ end of the human SLBP genomic sequence (McCombie et al. 1992) extending from the presumed promoter to the initiator ATG codon is shown. The putative TATAA box is boxed, the in-frame termination codons are underlined, and the putative Spl-binding sites in the proximal promoter are double-underlined. The sequence of the longest mouse cDNA obtained is aligned with the human SLBP sequence. The asterisks indicate the differences between the mouse and human sequence. $(C)$ The predicted protein sequences from the human, mouse, and frog SLBP cDNAs are compared. Identical amino acids are marked with an asterisk and similar amino acids with a dash. The minimal 73-amino-acid RNA-binding domain is overlined.

SLBP. There is significant homology between the frog and mammalian proteins over most of their length, although the amino and carboxyl termini differ between the frog and mammalian SLBPs. The SLBP does not resemble any other proteins in the data base, and in particular does not contain any of the previously described RNA-binding domains (Burd and Dreyfuss 1994). The protein is not basic, with a predicted pI of 7.4, and contains similar amounts of aspartic and glutamic acid as lysine and arginine.

\section{The cloned SLBP binds specifically to the stem-loop}

Previously, the molecular mass of the mouse SLBP has been estimated at $\sim 45 \mathrm{kD}$ based on SDS-gel electropho- resis of UV cross-linked SLBP and Northwestern analysis of both polyribosomal and nuclear SLBP (Pandey et al. 1991; Hanson et al. 1996). To determine whether the cloned SLBP was bound to the stem-loop, the human SLBP cDNA and several mutant human SLBP cDNAs with amino- and carboxy-terminal deletions (diagrammed in Fig. 4A) were transcribed with T7 RNA polymerase and the RNA was translated in a rabbit reticulocyte lysate (Fig. 4B).

There was a major polypeptide with a mobility of 45 $\mathrm{kD}$ synthesized in the reticulocyte lysate programmed with RNA transcribed from the SLBP cDNA (Fig. 4B, lane 1). A similar size was obtained when the human SLBP was synthesized in frog oocytes after injection of the mRNA or in a wheat germ translation system (not 
Wang et al.

shown). This mobility is consistent with the cloned cDNA representing the previously characterized SLBP (Pandey et al. 1991; Hanson et al. 1996), and suggests that the discrepancy in molecular mass is attributable to an anomalous mobility of the SLBP on SDS-polyacrylamide gels (Fig. 4B, lane 1). Translation of the various deletion mutants gave the expected relative sizes, although all of these had slower mobilities than predicted from their molecular mass (Fig. 4B, lanes 2-6). In addition to the major polypeptide, a minor polypeptide was produced from the full-length cDNA and the carboxyterminal deletions. This polypeptide migrated slightly slower $(\sim 3-5 \mathrm{kD})$, suggesting that it may be a modified form of the SLBP (Fig. 4B, lanes 1-5). The modifications are presumably at the amino terminus as the aminoterminal deletions gave only a single component in the reticulocyte lysate (Fig. 4B, lane 6).

The selection procedure used in yeast demonstrated that the cloned SLBP fusion protein interacted specifically with the stem-loop in vivo. The fact that the same cDNA was recovered multiple times from two different species strongly supports the contention that this is the major polypeptide that recognizes specifically the stemloop. To demonstrate whether the cloned protein binds the stem-loop specifically, we also performed a mobility-shift assay with in vitro-translated SLBP. There was
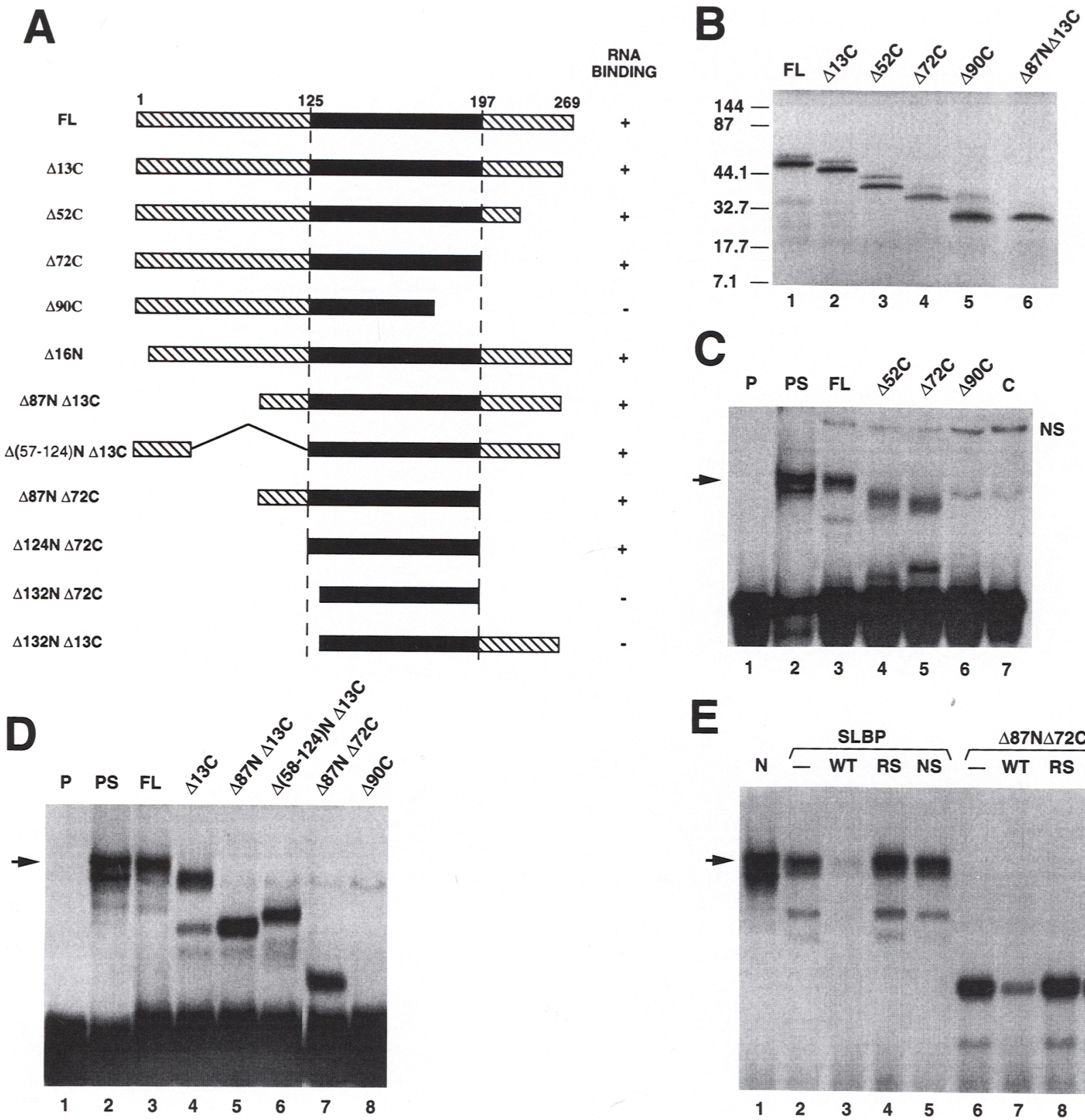

C
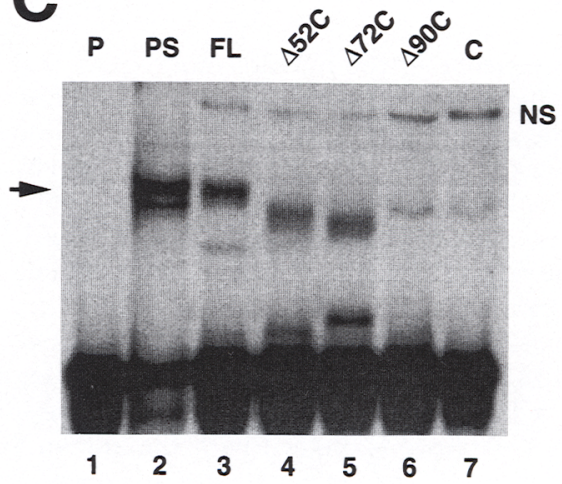

투
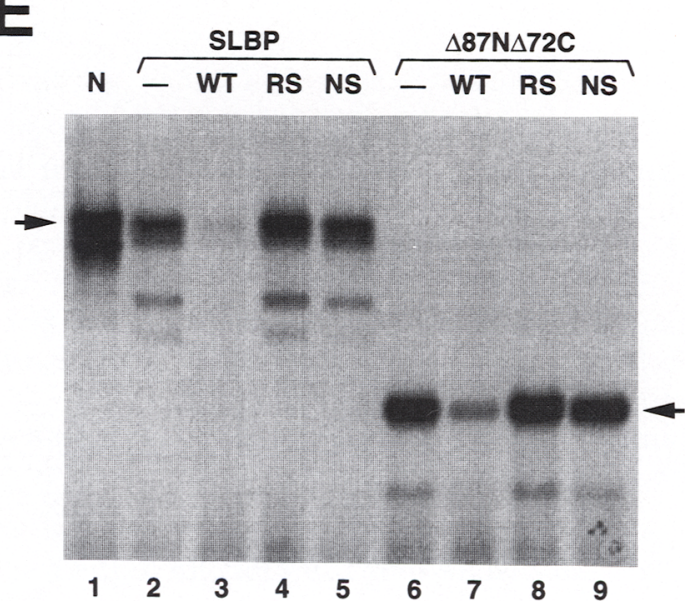

Figure 4. (See facing page for legend.) 
only a small amount of SLBP activity present in the reticulocyte lysate (Fig. 4C, lane 7). When the lysate was programmed with RNA encoding the SLBP, the amount of SLBP as determined by the mobility-shift assay increased dramatically (Fig. 4C, lane 3). The complex formed with the in vitro-translated SLBP had a similar mobility to the complex extracted from polyribosomes (Fig. 4C, lanes 2,3).

\section{The novel RNA-binding domain is a 73-amino-acid region}

To define further the sequences required for RNA binding, we made amino- and carboxy-terminal deletions. A series of $3^{\prime}$ deletions was constructed removing 13,52 , 72 , and 90 amino acids, respectively (Fig. 4A). These were all translated in the reticulocyte lysate giving products consistent with the expected reduced size of the deletions (Fig. 4B). The ability of each of these proteins to bind to the stem-loop was assessed using the mobilityshift assay. Removal of 52 or 72 amino acids from the carboxyl terminus did not affect binding to the RNA (Fig. $4 \mathrm{C}$, lanes 4,5), but removal of 90 amino acids abolished binding as measured by the mobility-shift assay (Fig. 4C, lane $6 ; 4 \mathrm{D}$, lane 8). Thus, the carboxy-terminal boundary of the RNA-binding site is between amino acids 179 and 197.

Removal of the first 16 amino acids did not affect the binding in vivo, as a clone with these amino acids deleted was selected in the yeast screen. Two additional amino terminal deletions were analyzed. One deletion had the first 87 amino acids removed, and the other deletion had amino acids 57-123 deleted. These clones were constructed from the gene with the carboxy-terminal 13 amino acids deleted. All three of these truncated proteins bound the stem-loop (Fig. 4D, lanes 5,6). A clone encoding the 110-amino-acid polypeptide (amino acids 88-197) was constructed and this small polypep- tide synthesized in the reticulocyte lysate. This small polypeptide also bound specifically to the stem-loop (Fig. 4D, lane 7). All of the deletion constructs formed similar amounts of complex with the stem-loop, suggesting that the deletions bound to the stem-loop with similar affinity. Both the binding of the full-length SLBP and the truncated SLBP were competed by the wild-type stem-loop (Fig. 4E, lanes 3,7) and were not competed by a mutant stem-loop with the stem sequence reversed or by a nonspecific RNA (Fig. 4E, lanes 4,5 and 8,9 ). Thus, the 110-amino-acid fragment bound the RNA with similar affinity and specificity as the full-length protein.

A minimal RNA-binding site of 73 amino acids extending from amino acids 125 to 197 can be deduced from these data (Fig. 4A), and this minimal 73-aminoacid binding site is approximately equal in molecular mass to the 26-nucleotide RNA target. To demonstrate that this 73-amino-acid region is sufficient for specific binding to the stem-loop, we constructed a clone to express only this portion of the SLBP. Because the small complex containing this polypeptide might not be readily detected by a mobility-shift assay, we attached five copies of a c-myc epitope tag to the amino terminus of this polypeptide. We also attached the same tag to the complete SLBP. After programming the reticulocyte lysate with the "tagged" full-length SLBP mRNA, there was a larger complex detected that bound to the stemloop as judged by the mobility-shift assay (Fig. 5A, lane 3). This c-myc tagged protein, which contains an additional 73 amino acids at the amino terminal, bound to the stem-loop (Fig. 5A, lane 3) and the complex was "shifted" by a c-myc antibody (Fig. 5A, lane 4). This result demonstrates that the recombinant protein synthesized in the reticulocyte lysate bound to the stemloop.

The c-myc tagged 73-amino-acid polypeptide also bound specifically to the stem-loop (Fig. 5B, lane 2). The complex was shifted by the anti-c-myc antibody (Fig. 5B,

Figure 4. A 73-amino-acid region of the cloned SLBP encodes the RNA-binding domain. (A) A series of deletions were constructed to map the RNA-binding domain of the SLBP. The central black region is the deduced RNA-binding domain. The hatched regions are the amino- and carboxy-terminal regions that are not essential for RNA binding. The numbers refer to the amino acids deleted from the carboxyl $(\mathrm{C})$ and amino $(\mathrm{N})$ termini, respectively. $(B)$ Translation of human SLBP and SLBP deletions in the reticulocyte lysate. The cloned DNAs were transcribed by T7 RNA polymerase and the RNA translated in the reticulocyte lysate for 90 min in the presence of $\left[{ }^{35} \mathrm{~S}\right]$ methionine. The products were analyzed by electrophoresis on $12 \%$ polyacrylamide gels and detected by autoradiography. (Lane 1) Full-length SLBP; (lanes 2-5); SLBP truncated 13, 52, 72, or 90 amino acids from the carboxyl terminus; (lane 6) SLBP with the first 87 and last 13 amino acids removed. $(C)$ Binding of the stem-loop by the carboxy-terminal deletions of SLBP. Fifteen femtomoles of radiolabeled stem-loop (lane 1) was incubated with $5 \mu \mathrm{g}$ of the polyribosomal extract (lane 2) or with $12.5 \mu$ l of reticulocyte lysate programmed with RNA encoding the full-length (lane 3) or the carboxy-terminal deletion mutants (lanes $4-6$ ). The mutants used are indicated above each lane. Lane 7 is incubation of $12.5 \mu \mathrm{l}$ of the unprogrammed reticulocyte lysate with the probe. The arrow indicates the complex with full-length SLBP and NS indicates a nonspecific complex formed in the reticulocyte lysate. $(D)$ Binding of aminoterminal deletions of the SLBP. Fifteen femtomoles of radiolabeled stem-loop (lane 1) was incubated with $5 \mu \mathrm{g}$ of the polyribosomal extract (lane 2) or with $12.5 \mu \mathrm{l}$ of reticulocyte lysate programmed with RNA from the full-length (lane 3) or deletion mutants (lanes 4-8|. The mutants used are indicated above each lane. The position of the complex with full-length SLBP is indicated by the arrow. (E) A 110-amino-acid RNA-binding fragment of SLBP specifically binds the stem-loop. In lane 1 the probe was incubated with a nuclear extract. In vitro-translated full-length SLBP (lanes 2-5) and the 110-amino-acid fragment $\Delta 87 \mathrm{~N} \Delta 72 \mathrm{C}$ (lanes $6-9$ ) were incubated on ice for 10 min with 15 femtomoles of labeled 30-nucleotide RNA containing the stem-loop. The complexes were resolved by electrophoresis on a $10 \%$ polyacrylamide gel. In lanes 3 and 7, a 100-fold excess of the 30-nucleotide RNA was included, in lanes 4 and 8 a 100 -fold excess of an RNA with the stem sequence reversed was included, and in lanes 5 and 9 a 100 -fold excess of a nonspecific RNA (AAAUACCUACUUCAUACAA) was included. The arrows indicate the specific complexes formed. The unbound probe has been run off the gel to allow good resolution of the complex with the 110-amino-acid protein. 
Figure 5. A c-myc tagged 73-amino-acid polypeptide binds the stem-loop specifically. (A) The reticulocyte lysate was programmed with a DNA encoding SLBP with five copies of a c-myc tag (73 amino acids) added to the amino terminus. The reticulocyte lysate $(12.5 \mu 1)$ was incubated with 15 femtomoles of labeled probe (lanes 3,4). Anti-c-myc antibody was then added to the reaction in lane 4 . (Lane 1) Probe alone; (lane 2) the complex formed in a nuclear extract from mouse myeloma cells; (lane 5) incubation in unprogrammed reticulocyte lysate. The bands labeled $\mathrm{N}$ and $\mathrm{N}_{\mathrm{M}}$ (myc-tagged) represent the specific complexes and bands labeled NS are the nonspecific complexes. $(B)$ The reticulocyte lysate was programmed with cloned DNA encoding the $\Delta 132 N \Delta 72 \mathrm{C}$ polypeptide containing the five copies of the c-myc tag (lane 1) or with the $\Delta 124 \mathrm{~N} \Delta 72 \mathrm{C}$ polypeptide containing five copies of the c-myc tag (lanes 2-5). The
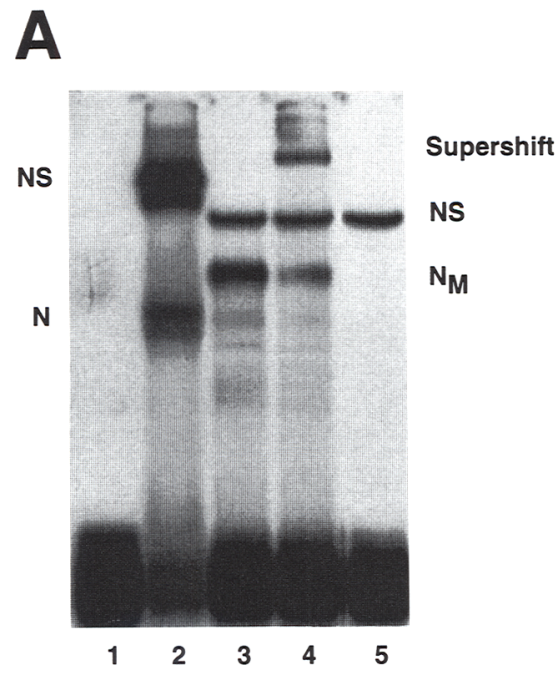
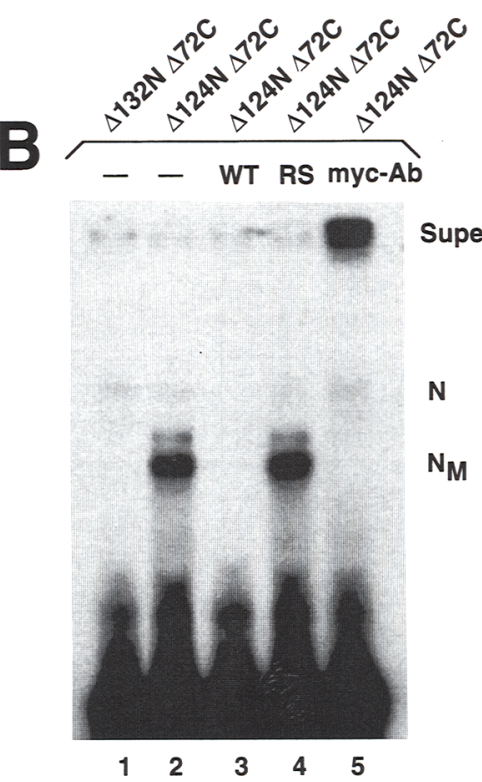

lysate was incubated with 15 femtomoles of labeled wild-type probe in the absence of competitor (lane 2), or in the presence of a 100 -fold excess of the wild-type stem-loop (lane 3), or the reverse-stem competitor (lane 4). One microliter of the c-myc antibody was added to the reaction in lane 5 after the incubation. Band $N$ is the native SLBP present in low levels in the reticulocyte lysate and band $\mathrm{N}_{\mathrm{M}}$ is the complex with the myc-tagged polypeptide.

lane 5) and was also competed by the wild-type competitor but not by the reverse-stem mutant (Fig. 5B, lanes $3,4)$. A c-myc tagged polypeptide with 8 additional amino acids deleted did not bind to the stem-loop as judged by the mobility-shift assay (Fig. 5B, lane 1). Thus, the amino terminal boundary of the RNA-binding domain is located near amino acid 125 and the 73-amino-acid region from amino acids 125 to 197 contains all the information necessary for specific binding to the stem-loop. This 73amino-acid region also binds specifically to the stemloop RNA when it is expressed as a glutathionine $S$-transferase (GST) fusion protein in $E$. coli (L. Zheng, Z.-F. Wang, and W.F. Marzluff, unpubl.).

This 73-amino-acid RNA-binding site loverlined in Fig. $3 \mathrm{C}$ ) is $\sim 20 \%$ lysine and arginine and is the most basic region of SLBP. Although the binding site is very conserved among the three vertebrate SLBPs, there are other equally conserved regions that are not essential for RNA binding, and these presumably mediate other functions of the SLBP (Fig. 3C).

\section{SLBP is the major protein that binds the stem-loop in nuclear and polyribosomal extracts}

To demonstrate conclusively that the cloned SLBP is the protein that we have detected previously in both nuclear and polyribosomal extracts, we generated antibodies directed against the carboxyl terminus of the cloned mouse SLBP using a 13-amino-acid synthetic peptide coupled to keyhole limpet hemocyanin. The antibodies were purified from the serum by chromatography on protein A-Sepharose. The 26-nucleotide probe, containing the wild-type stem-loop, was incubated with a nuclear extract and then the antibody added. The antibody to the carboxyl terminus of the cloned SLBP shifted $>95 \%$ of the complex (Fig. 6A, lane 5), whereas the preimmune serum and antibody directed against the carboxyl terminus of human cyclin D3 had no effect on the binding (Fig. $6 \mathrm{~A}$, lanes 3,4$)$. Addition of the 13 -amino-acid carboxyterminal peptide to the reaction prevented the supershift (Fig. 6A, lane 6). Similar results were found with the polyribosomal extract. The anti-SLBP shifted all the binding activity that was extracted from polyribosomes (Fig. 6B, lane 5), and again the binding of the antibody was competed by the synthetic peptide (Fig. 6B, lane 6). Thus, all the specific binding activity to the stem-loop in both the nuclear and polyribosomes detected using the mobility-shift assay is attributable to the SLBP that we have cloned.

The antibody raised against the carboxy-terminal of SLBP was also tested by Western blotting on nuclear and polyribosomal extracts. The antibody specifically recognized two bands of $\sim 45$ and $40 \mathrm{kD}$ in both the nuclear and polyribosomal extracts (Fig. 6C). The relative amounts of these two bands varied from extract to extract and in many extracts the upper $45-\mathrm{kD}$ band was predominant (cf. Fig. 6C with Fig. 7A). Binding of the antibody to both polypeptides was specific, and was competed by the carboxy-terminal peptide used for immunization (Fig. 6C, lanes 5,6 ) but not by a peptide containing the first 15 amino acids of SLBP (Fig. 6C, lanes $3,4)$. In the mobility-shift experiments it is common to see two closely spaced complexes (Fig. 4C-E and Fig. 6B), and it is possible that the two polypeptides represent different forms of SLBP that may form these two complexes. The two forms of SLBP could result either from 

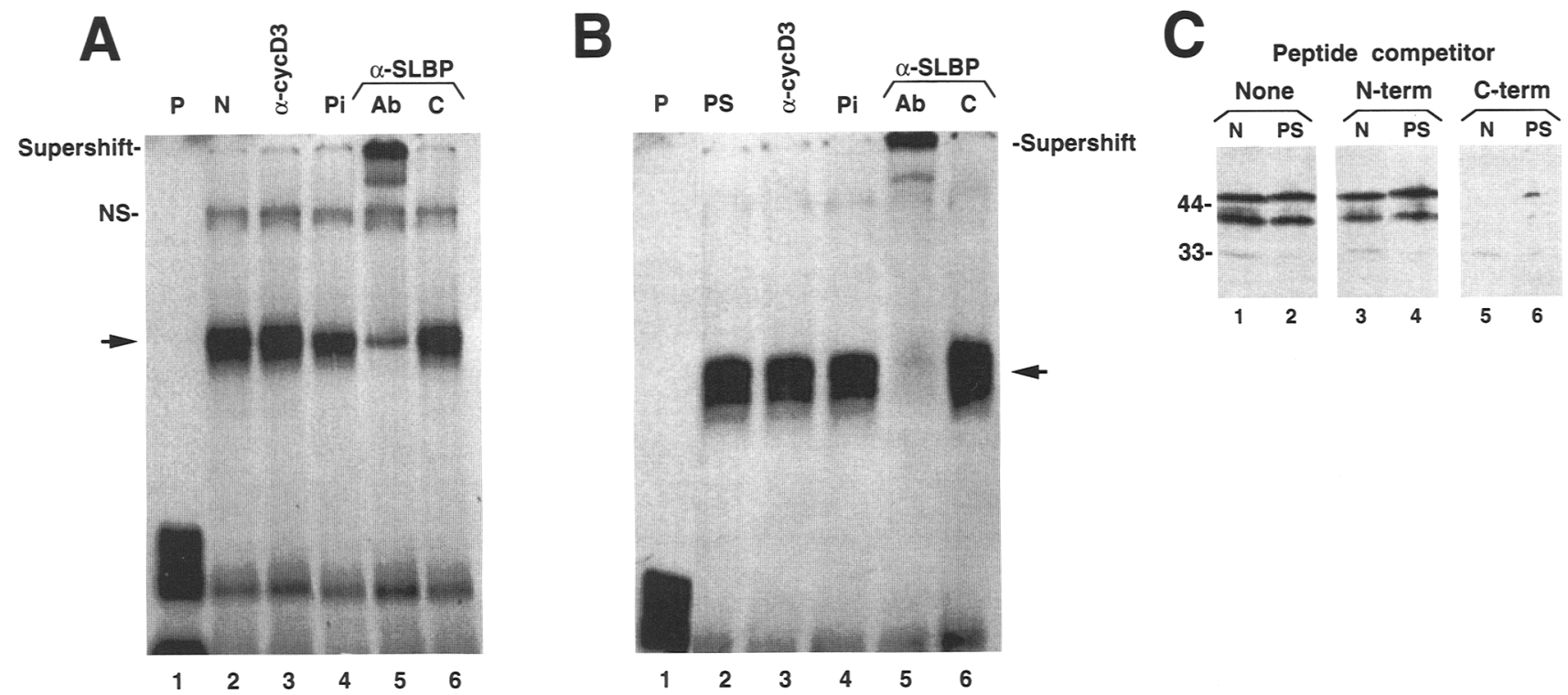

Figure 6. Antibody to the SLBP reacts with the major complex that binds the stem-loop. (A) Nuclear extract (15 $\mu \mathrm{g})$ was incubated with 15 femtomoles of the radiolabeled stem-loop. After incubation, $1 \mu$ l of anti-cyclin D3 antibody (lane 3), preimmune serum (lane 4), or anti-SLBP antibody (lanes 5,6) was added to the reaction. In lane 6,1 $\mu \mathrm{g}$ of competitor carboxy-terminal peptide was also added. The specific complex is indicated by an arrow and NS is a nonspecific complex. The band labeled $P$ is the probe (lane 1). (B) Polyribosomal extract was incubated with 15 femtomoles of the radiolabeled stem-loop. After incubation, $1 \mu l$ of anti-cyclin D3 antibody (lane 3), preimmune serum (lane 4), or anti-SLBP antibody (lanes 5,6) was added to the reaction. In lane 6,1 $\mu \mathrm{g}$ of competitor carboxy-terminal peptide was also added. The specific complex is indicated by an arrow. $(C)$ Fifty micrograms of protein from nuclear or polyribosomal extracts were resolved by electrophoresis on $10 \%$ SDS-polyacrylamide gels, transferred to nitrocellulose, and incubated with the anti-SLBP antibody in the absence (lanes 1,2) or presence of competitor synthetic peptide $(1 \mu \mathrm{g} / \mathrm{ml})$ corresponding to the amino terminus (lanes 3,4) or carboxyl terminus (lanes 5,6) of SLBP.

post-translational modification or from proteolysis (see Discussion).

\section{Depletion of SLBP reduces the efficiency of histone pre-mRNA processing}

Histone pre-mRNA processing requires two defined trans-acting factors, U7 snRNP, which is absolutely required for processing (Mowry and Steitz 1987b; Cotten et al. 1988) and HBF, which is not absolutely required for processing in vitro (Mowry et al. 1989; Streit et al. 1993). The degree of dependence of processing on HBF is variable with different extracts and with different substrates (Streit et al. 1993). Thus, addition of an RNA containing the stem-loop will reduce but not abolish processing (Streit et al. 1993; Dominski et al. 1995). Previously we showed by depleting a nuclear extract with a biotinylated RNA that HBF (and all the SLBP) could be removed from the extract resulting in a reduction in processing (Dominski et al. 1995).

The anti-SLBP antibody was capable of depleting the binding activity from a nuclear extract. Aliquots of a nuclear extract were incubated with a protein A-Sepharose either after incubation with preimmune serum or with anti-SLBP antibody. The depleted extracts were then assayed for the presence of SLBP by Western blotting, the ability to bind the stem-loop, and the ability to process histone pre-mRNA. Both bands on the Western blot (45 $\mathrm{kD}$ and $40 \mathrm{kD}$ ) recognized in the nuclear extract by the anti-SLBP antibody were depleted specifically by the anti-SLBP antibody (Fig. 7A, lane 3), but not by the preimmune serum (Fig. 7A, lane 2). Similarly the binding activity was also removed from the extract depleted with the anti-SLBP antibody but not from the mock-depleted extract (Fig. 7B, lanes 4,5). Thus, essentially all of the SLBP, as detected by both Western blotting and the binding assay, was removed from the extract.

The ability of the nuclear extract and the depleted extracts to process a synthetic 320-nucleotide histone premRNA was determined. This extract had a strong dependence on the stem-loop, and processing was reduced $\sim 85 \%$ by the addition of excess wild-type stem-loop (Fig. 7C, lanes 2,3 ). Processing activity was slightly reduced $(25 \%)$ by mock depletion of the extract (Fig. $7 \mathrm{C}$, lane 4), but was reduced significantly (fourfold) by depletion with the anti-SLBP antibody (Fig. 7C, lane 5). Removal of the SLBP with the antibody reduced processing to a similar extent as addition of the wild-type competitor RNA, indicating that the SLBP is a component of the processing machinery.

These results are consistent with our previous result suggesting that the SLBP is, or is a component of, HBF (Dominski et al. 1995). We have not yet been able to restore processing to a depleted extract because of our inability to express active recombinant SLBP (see Discussion). 
We have cloned a novel RNA-binding protein, SLBP, from three vertebrate species, that binds specifically to the $3^{\prime}$ end of histone mRNA. SLBP contains a small RNA-binding domain and is likely to be the critical trans-acting factor involved in many aspects of the metabolism of histone mRNA as well as the post-transcriptional regulation of histone mRNA during the cell cycle. It is clearly involved in the only processing reaction needed for histone mRNA biogenesis.

\section{Discussion}

The three-hybrid system devised by Wickens and coworkers (SenGupta et al. 1996) has the potential to allow isolation of rare RNA-binding proteins. The SLBP is an ideal candidate for using this technique, as the RNA target sequence is small and well-defined and is not present in yeast RNA. In addition, the SLBP binds extremely tightly and stably to its target sequence (Williams and Marzluff 1995), increasing the likelihood that discriminating conditions can be developed that would allow selection of positive clones. Indeed $\sim 80 \%$ of the positive clones from the initial screen (his ${ }^{+}$and blue) contained the SLBP. When these clones were reselected with a mutant stem-loop that does not bind SLBP, $100 \%$ of the clones that did not interact with the mutant stem-loop contained the SLBP, and multiple independent clones were obtained from both the frog and human libraries, suggesting that the selection was very efficient. The other $20 \%$ presumably represent clones that encode general RNA-binding proteins, proteins that interact with the MS2 protein or that interact directly with the DNA. The same cDNA also has been isolated from a human library by Muller, Schümperli, and coworkers (Martin et al. 1997) using this same system. They have demonstrated also that the cloned protein is involved in histone pre-mRNA processing by complementing an extract deficient in processing with the recombinant SLBP (Martin et al. 1997).

The SLBP is a novel RNA-binding protein. A number of different types of RNA-binding domains have been identified in the past few years, and there are multiple examples of proteins with different binding specificities that are members of each of these classes (Burd and Dreyfuss 1994; Draper 1995). It is possible that there will be other RNA-binding proteins that have a similar RNAbinding domain as the SLBP but with different specificities. The $3^{\prime}$ end of histone mRNA has been highly conserved in all metazoans and factors that interact with the stem-loop have been detected in all metazoans examined so far, including Drosophila and sea urchins ( $T$. Robertson, J. Howard and W.F. Marzluff, unpubl.). Highaffinity binding of the SLBP requires the 26-nucleotide sequence at the $3^{\prime}$ end of the histone mRNA, and mutagenesis experiments have indicated that the sequence of the stem is the most critical feature for high affinity binding (Williams and Marzluff 1995). It is likely that the SLBP is binding a particular novel three-dimensional structure assumed by the $3^{\prime}$ end of histone mRNA.

The sequence of the SLBP has been highly conserved between mammals and frogs. In addition to the conserved RNA-binding domain, which is expected, there is also extensive identity in the amino-terminal region between amino acids 55 and 125, as well as in the carboxyterminal region of the SLBP. These conserved amino acid sequences probably play a role in the various functions of SLBP in histone mRNA metabolism.

We have shown here specifically that the SLBP we cloned is the major protein that binds to the $3^{\prime}$ end of histone mRNA as detected by the RNA-binding assay. Using antibodies specific for the carboxyl terminus of the SLBP, we have demonstrated that the SLBP is the major binding activity present in both the nucleus and the polyribosomes, in agreement with our previous conclusion that the same polypeptide functions in both compartments (Pandey et al. 1991; Dominski et al. 1995; Hanson et al. 1996). There are two forms of SLBP detected by Western blotting (Figs. 6C and 7A). We have observed that nuclear extracts containing predominantly the slower migrating form of SLBP are more active in histone pre-mRNA processing (Z. Dominski, unpubl.). These two forms could result from post-translational modification of SLBP, and probably account for the fact that the complexes observed by mobility shift are often doublets (Fig. 4). Alternatively the faster migrating form could be a result of proteolysis from the amino terminus. When the antibody was used to remove SLBP from a nuclear extract (as assayed by Western blotting and mobility-shift assay/ the depleted extract has a reduced ability to process histone pre-mRNA, suggesting that SLBP is, or is a component of, the hairpin-binding factor, as we have suggested previously (Dominski et al. 1995).

Although we have been successful in removing SLBP from the extract and reducing processing activity, we have not yet been successful in reconstituting processing with purified recombinant SLBP. Truncated forms of SLBP that are active in binding the stem-loop have been expressed in bacteria (L. Zhang and W.F. Marzluff, unpubl.) but because the full-length SLBP is toxic to bacteria, we have not yet been able to prepare full-length active recombinant SLBP.

The $3^{\prime}$ end of mRNA is important in many aspects of mRNA metabolism. The poly(A) tail is necessary for efficient translation of mRNAs (Jackson and Standart 1990) and is important in determining the half-life of mRNAs (Bernstein and Ross 1989; Decker and Parker 1994). The function of the poly(A) tail is mediated by the poly(A) binding protein (PABP) that is present as a component of the mRNP (Bernstein and Ross 1989). Similarly, the 3' end of histone mRNA is also necessary for efficient transport and translation of the mRNA (Sun et al. 1992; Williams et al. 1994), as well as being essential for regulation of histone mRNA half-life (Pandey and Marzluff 1987). Because the histone mRNA is degraded $3^{\prime}$ to $5^{\prime}$, it is likely that SLBP (as part of the histone mRNP/ plays a critical role in the degradation of histone mRNA. Unlike the PABP, the SLBP also participates in the nuclear metabolism of pre-mRNA, and is required for efficient histone pre-mRNA processing (Dominski et al. 1995). Thus, it joins a growing family of pro- 

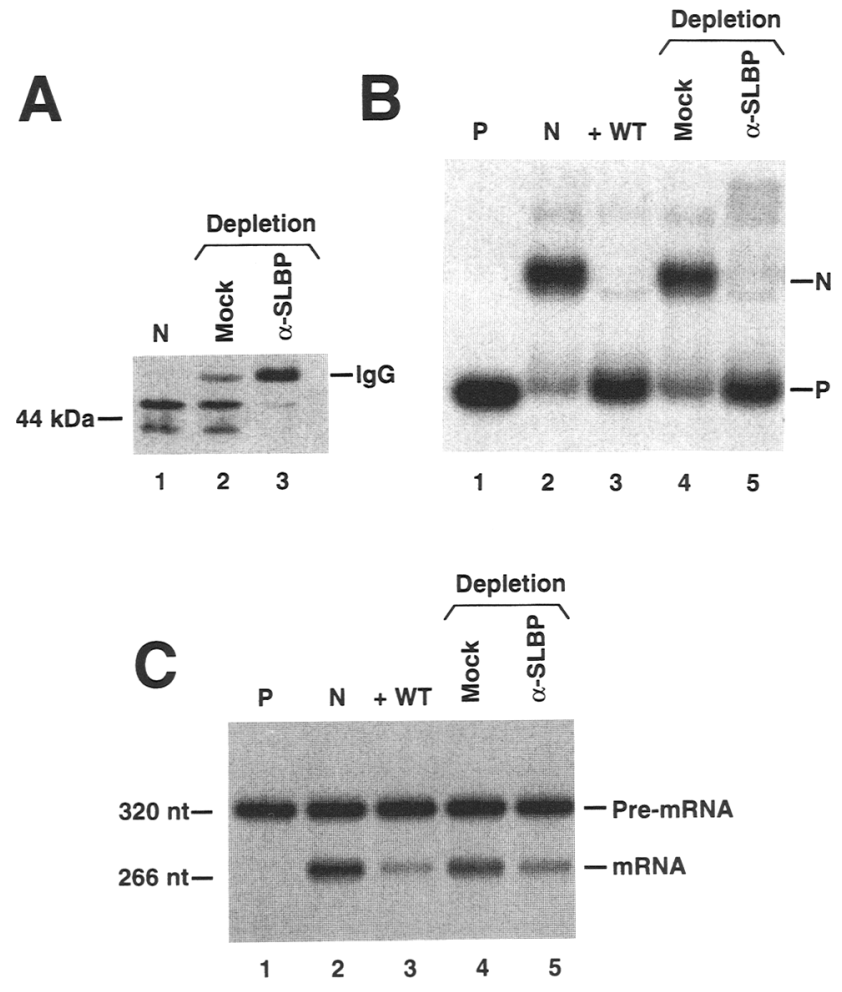

Figure 7. Depletion of the SLBP from the nuclear extract reduces processing efficiency. Nuclear extract was incubated either with preimmune serum (mock-depleted) or with anti-SLBP antibody and then passed over protein A-Sepharose. Aliquots of the extracts were then assayed for SLBP activity by Western blotting $(A)$, mobility-shift $(B)$, and processing of histone premRNA $(C) .|A|$ Equal volumes of the nuclear extract (lane 1), the mock-depleted extract (lane 2), or the extract depleted with antiSLBP (lane 3) were analyzed by Western blotting. The major polypeptide detected was the $45-\mathrm{kD}$ polypeptide with a small amount of the $40-\mathrm{kD}$ polypeptide in this extract. There was a small amount of rabbit IgG present in the depleted extracts (lanes 2,3), which is detected by the secondary antibody. $(B)$ The extracts were assayed for binding activity using a 30-nucleotide probe and the mobility-shift assay. Five microliters $(25 \mu \mathrm{g})$ of the nuclear extract (lane 2), the mock-depleted extract (lane 4), or the anti-SLBP-depleted extract (lane 5) were incubated with the radiolabeled probe, and the complexes were resolved by native gel electrophoresis. Lane 3 is nuclear extract in the presence of competitor wild-type RNA and lane 1 is the probe. N indicates the specific complex and $\mathrm{P}$ indicates the unbound probe. (C) The extracts were assayed for ability to process a 320-nucleotide histone pre-mRNA substrate. The pre-mRNA was incubated with $17 \mu \mathrm{l}(85 \mu \mathrm{g})$ of nuclear extract (lane 2), mock-depleted extract (lane 4 ), or extract depleted with the anti-SLBP antibody (lane 5). In lane $3,1 \mu \mathrm{g}$ of a 30-nucleotide wild-type stem-loop was added to the nuclear extract before the addition of the substrate. Lane 1 is the unprocessed substrate. RNA was purified from each reaction, analyzed by $7 \mathrm{M}$ urea-polyacrylamide gel electrophoresis, and the products were detected by autoradiography. teins, including heterogenous nuclear ribonucleoprotein (hnRNP) Al (Piñol-Roma and Dreyfuss 1992; Michael et al. 1995) and rev (Kalland et al. 1994), which may bind to pre-mRNA and then accompany the mature mRNA to the cytoplasm.

Despite the similarities in function in cytoplasmic mRNA metabolism between SLBP and PABP, there is no obvious sequence similarity between these two proteins. The PABP binds the poly(A) tail through four RNP domains (Nietfeld et al. 1990; Burd et al. 1991) and, in addition, has a carboxy-terminal domain presumably responsible for mediating other functions of the PABP through protein-protein interactions. SLBP has a conserved central domain that is necessary for RNA binding. Extensive regions of the amino and carboxyl termini of the SLBP are also conserved in vertebrate SLBPs, and we are currently investigating possible functions for these conserved regions. SLBP is likely to be one of the critical trans-acting factors that mediate the post-transcriptional regulation of histone mRNA levels, coupling them tightly to DNA replication. The availability of SLBP should allow the determination of the molecular details of how the 3' end of histone mRNA functions in the various metabolic steps in histone mRNA metabolism as well as in the post-transcriptional regulation of histone mRNA levels.

\section{Materials and methods}

\section{The three-hybrid screen}

The L40-coat strains and plasmids pMS2-1, and pIIIEx426RPR (SenGupta et al. 1996) were a gift of Dr. Marv Wickens (University of Wisconsin). The plasmid $\mathrm{pMS}-\mathrm{SL}_{\mathrm{WT}}$ was constructed by digesting plasmid pMS2-1 with XmaIII and SpeI and insertion of a 39-nucleotide double-stranded oligonucleotide containing the wild-type stem-loop sequence and a RNA polymerase III termination site (see Fig. 1). The plasmid pIII/MS-SL $\mathrm{ST}_{\mathrm{WT}}$ was constructed by digesting the plasmid pMS2-SL $\mathrm{WT}_{\mathrm{WT}}$ with $E c O R I$ and inserting the 170-nucleotide fragment into pIIIEx426RPR. The plasmid $\mathrm{pMS} 2-\mathrm{SL}_{\mathrm{RM}}$ was constructed by inserting a double-stranded oligonucleotide containing the stemloop with the sequence of the stem reversed (see Fig. 1B) and then the plasmid $\mathrm{pIII} / \mathrm{MS}-\mathrm{SL}_{\mathrm{RM}}$ was constructed by inserting the 170-nucleotide EcoRI fragment into pIIIEx426RPR. The proper orientation of the insert was confirmed by sequencing. Each of these plasmids was introduced into the yeast strain L40-coat by transformation and selection on ura $^{-}, \operatorname{trp}^{-}$plates. The resulting yeast strains L40-coat/WT and L40-coat/RM were used in subsequent experiments. The HeLa cell two-hybrid cDNA library cloned in pGAD-GH was a gift of Dr. Yue Xiong (University of North Carolina, Chapel Hill) and the Xenopus oocyte two-hybrid cDNA library cloned in pGAD10 was obtained from Clontech. Two hundred micrograms of plasmid DNA from each library was transformed into competent yeast L40-coat/WT cells as described by Clontech. The yeast were plated on leu ${ }^{-}$, ura $^{-}$, trp $^{-}$, his ${ }^{-}$plates containing $5 \mathrm{~mm}$ aminotriazole. Nineteen aminotriazole-resistant colonies were obtained from $2 \times 10^{6}$ transformants from the HeLa cell cDNA. These colonies were then plated on indicator plates and the six blue colonies selected. Plasmid DNA was prepared from each blue colony, rescued by transfection into $E$. coli $\mathrm{HB} 101$ by selection on leu- plates, and the plasmid DNA was purified from 
each colony. The plasmid DNA was then introduced into the yeast strain L40-coat/RM, which contained the plasmid pIII/ MS-SL $\mathrm{RM}_{\mathrm{RM}}$ encoding the reverse-stem bait RNA. Plasmids that did not activate the $l a c Z$ gene in strains containing the reversestem RNA as bait were sequenced. These plasmids (five from the human screen and seven from the Xenopus screen/ were independent clones of the same cDNA. The full-length human SLBP cDNA was digested with EcoRI upstream of the initiator methionine and SpeI in the $3^{\prime}$ untranslated region and cloned into pGEM3zf digested with EcoRI and $X b a I$ for construction of the deletion mutants and transcription by T7 RNA polymerase.

Isolation of mouse SLBP $c D N A$ and additional human SLBP cDNA clones

A mouse cDNA library $(\lambda \operatorname{ExL} \operatorname{Lox}(+)$, Novagen) prepared from BB4 cells was screened using the 890 -nucleotide fragment of the human SLBP containing the $5^{\prime}$ end of the cDNA as a probe. Six phage were obtained, all encoding different parts of the same cDNA. The longest insert, 1.6-kb, contained a near full-length cDNA clone. Additional human cDNA clones were isolated by screening a cDNA library prepared from HeLa cell DNA with the same probe. All of the five positive phage obtained encoded the same cDNA as was isolated in the three-hybrid screen and none extended further $5^{\prime}$ than the longest clone obtained from the yeast three-hybrid screen. The GenBank accession nos. for the human mouse, and Xenopus SLBP clones are U75679, $\mathrm{U} 75680$, and U75681, respectively.

\section{Construction of the deletion mutants}

The deletion mutants were constructed using restriction enzyme sites in the human SLBP clone. Digestion with HindIII removed 13 amino acids, digestion with $P_{s t I}$ removed 52 amino acids, digestion with BamHI removed 72 amino acids, and finally, digestion with Sall removed 90 amino acids from the carboxyl terminus. For the amino terminal deletion of 87 amino acids, the gene truncated at HindIII was digested with $\mathrm{NcoI}$ at the initiator methionine and the $\mathrm{NcoI}$ site was filled in with the Klenow fragment of DNA polymerase I. The gene was then digested with $\mathrm{HpaI}$ removing a 260 -nucleotide fragment and the resulting plasmid religated. To generate the deletion of amino acids 58-124, the gene truncated at HindIII was digested with AvaI (at amino acid 57) and with NaeI at amino acid 124. The DNA was incubated with the Klenow fragment of DNA polymerase and deoxynucleotide triphosphates to fill in the AvaI overhang. The plasmid was then religated resulting in an inframe deletion.

To construct the $\Delta 87 \mathrm{~N} \Delta 72 \mathrm{C}$ gene, the plasmid containing the $\Delta 87 \mathrm{~N}$ gene was digested with $B a m H I$ and HindIII to remove the carboxy-terminal region of the protein, the ends filled in with DNA polymerase and religated. For production of the myctagged SLBP, the mouse SLBP DNA was digested with ApaI in the polylinker 3' of the gene and the overhang was blunted with T4 DNA polymerase. The fragment containing the SLBP was excised subsequently with $\mathrm{NcoI}$ at the initiator methionine and ligated into plasmid MT6 (a gift of Mark Roth, Seattle), digested with $\mathrm{Ncol}$ between the fifth and sixth 11 amino acid myc tag in the vector. The $\Delta 124 \mathrm{~N} \Delta 72 \mathrm{C}$ and $\Delta 132 \mathrm{~N} \Delta 72 \mathrm{C}$ genes were constructed by PCR using appropriate primers containing an NcoI site for the amino-terminal boundary. The PCR product was digested with $N c o I / B a m H I$ and the resulting fragment cloned into plasmid MT6, resulting in five copies of a c-myc tag on these polypeptides.

\section{In vitro translation}

For in vitro translation the cloned DNA was linearized and then incubated in the TNT coupled transcription-translation reticulocyte lysate (Promega; 25- $\mu \mathrm{l}$ reaction as described by the manufacturer) for $90 \mathrm{~min}$. To visualize the protein product, $15-\mu \mathrm{l}$ reactions containing $15 \mu \mathrm{Ci}$ of $\left[{ }^{35} \mathrm{~S}\right]$ methionine were used and the reactions were analyzed by SDS-polyacrylamide gel electrophoresis followed by autoradiography. For reactions that were used for the binding assays, the $\left[{ }^{35} \mathrm{~S}\right]$ methionine was omitted and a 1:1 mix of amino acids minus methionine plus amino acids minus leucine supplied by the manufacturer were used.

\section{Antisera}

A synthetic peptide corresponding to the last 13 amino acids of the mouse SLBP sequence was synthesized in the University of North Carolina (UNC) peptide synthesis facility and purified by reverse-phase HPLC. Ten milligrams of peptide was coupled to $10 \mathrm{mg}$ of keyhole limpet hemocyanin. The keyhole limpet hemocyanin-coupled peptide was injected into two rabbits and serum was collected after the second injection (Pocono Farms, PA). To purify the immunoglobulin, $0.5 \mathrm{ml}$ of serum was passed over a $0.5-\mathrm{ml}$ column of protein A-Sepharose, the column washed with 10 volumes of $100 \mathrm{~mm}$ Tris $(\mathrm{pH} 8.0)$, followed by 10 volumes of $10 \mathrm{~mm}$ Tris $(\mathrm{pH} 8.0)$. The antibody was eluted with $100 \mathrm{~mm}$ glycine $(\mathrm{pH} 3.0)$, neutralized and stored at $4^{\circ} \mathrm{C}$ (Harlow and Lane 1988). As a control, an antihuman cyclin D3 antibody raised against the carboxy-terminal peptide of mouse human cyclin D3 was used (a gift of Drs. Dawn Phelps and Yue Xiong). Western blots were performed by standard procedures (Harlow and Lane 1988).

\section{Mobility-shift assays}

Mobility-shift assays were performed using a radiolabeled 30nucleotide stem-loop RNA prepared by transcription of oligonucleotide templates as described previously (Pandey et al. 1991). Twenty-five microliters of reticulocyte lysate programmed with the appropriate RNAs were used for the binding reactions. The lysates were mixed with 15 femtomoles of labeled RNA probe and $25 \mu \mathrm{l}$ of buffer $[10 \%$ glycerol, $5 \mathrm{~mm}$ $\mathrm{Mg}(\mathrm{OAc})_{2}, 20 \mathrm{~mm}$ triethanolamine $(\mathrm{pH} 7.8), 10 \mathrm{mM} \mathrm{KCl}, 0.5$ $\mathrm{mg} / \mathrm{ml}$ of BSA, $0.5 \mathrm{mg} / \mathrm{ml}$ of yeast tRNA, $20 \mathrm{~mm}$ EDTA, and 2 $\mathrm{mM}$ dithiothreitol] and incubated on ice for $10 \mathrm{~min}$ followed by a 5-min incubation at room temperature. The reactions were analyzed on $8 \%$ or $10 \%$ polyacrylamide gels under nondenaturing conditions and the complexes detected by autoradiography. Polyribosomal and nuclear extracts were prepared as described previously and assayed under the same conditions (Pandey et al. 1991).

For the supershift assays on the myc-tagged polypeptides, $1 \mu \mathrm{l}$ of anti c-myc antibody (9E10, Oncogene Sciences) was added to each reaction after the initial incubation and the incubation was continued for $5 \mathrm{~min}$ at room temperature.

\section{In vitro processing}

A pre-mRNA containing the $3^{\prime}$ end of the mouse histone $\mathrm{H} 2 \mathrm{a}$ gene was used for the in vitro processing reactions. A synthetic pre-mRNA was synthesized using T7 RNA polymerase and labeled with $\left[\alpha^{-32} \mathrm{P}\right]$ CTP. Nuclear extracts were prepared from mouse myeloma cells as described previously and the processing reaction carried out for $30 \mathrm{~min}$ at $32^{\circ} \mathrm{C}$ exactly as described previously (Dominski et al. 1995). To deplete the SLBP from the nuclear extract, $10 \mu \mathrm{l}$ of anti-SLBP IgG was added to $200 \mu \mathrm{l}$ of 
extract and the extract incubated on ice for $1 \mathrm{hr}$. Forty microliters of prewashed protein A-agarose beads were added to the extract and incubated on ice for $30 \mathrm{~min}$. The protein A-agarose beads were removed by centrifugation at $2000 \mathrm{rpm}$ for $3 \mathrm{~min}$. The extract was collected and used for both mobility shift and RNA processing assays.

\section{Acknowledgments}

This work was supported by grant GM29832 from the National Institutes of Health to W.F.M. We thank Marv Wickens for providing the strains for the yeast three-hybrid system before publication, Dani Schümperli for communicating results before publication and for many helpful discussions, Yue Xiong and Dawn Phelps for a gift of the anti-human cyclin D3 antibody, Laura Livingstone and Jenifer Langdon of the University of North Carolina (UNC) DNA Sequencing Facility and Alan Locke of the UNC Peptide Synthesis Facility for their outstanding assistance, and Jan Sumerel for critical comments on the manuscript. A manuscript describing similar findings was submitted by Schümperli, Muller, and coworkers (Martin et al. 1997) at the same time this paper was submitted and will be published in the January 1997 issue of EMBO Journal.

The publication costs of this article were defrayed in part by payment of page charges. This article must therefore be hereby marked "advertisement" in accordance with 18 USC section 1734 solely to indicate this fact.

\section{References}

Bernstein, P. and J. Ross. 1989. Poly(A), poly(A) binding protein and the regulation of mRNA stability. Trends Biochem. Sci. 14: 373-377.

Bond, U.M., T.A. Yario, and J.A. Steitz. 1991. Multiple processing-defective mutations in a mammalian histone premessenger RNA are suppressed by compensatory changes in U7 RNA both in vivo and in vitro. Genes \& Dev. 5: 1709-1722.

Burd, C.G. and G. Dreyfuss. 1994. Conserved structures and diversity of functions of RNA-binding proteins. Science 265: 615-621.

Burd, C.G., E.L. Matunis, and G. Dreyfuss. 1991. The multiple RNA-binding domains of the mRNA poly(A)-binding protein have different RNA-binding activities. Mol. Cell. Biol. 11: 3419-3424.

Cotten, M., O. Gick, A. Vasserot, G. Schaffner, and M.L. Birnstiel. 1988. Specific contacts between mammalian U7 snRNA and histone precursor RNA are indispensable for the in vitro RNA processing reaction. EMBO I. 7: 801-808.

Decker, C.J. and R. Parker. 1994. Mechanisms of mRNA degradation in eukaryotes. Trends Biochem. Sci. 19: 336-340.

Dominski, Z., J. Sumerel, R.J. Hanson, and W.F. Marzluff. 1995. The polyribosomal protein bound to the $3^{\prime}$ end of histone mRNA can function in histone pre-mRNA processing. RNA 1: 915-923.

Draper, D.E. 1995. Protein-RNA recognition. Annu. Rev. Biochem. 64: 593-620.

Gick, O., A. Krämer, A. Vasserot, and M.L. Birnstiel. 1987. Heat-labile regulatory factor is required for $3^{\prime}$ processing of histone precursor mRNAs. Proc. Natl. Acad. Sci. 84: 89378940.

Hanson, R.J., J.-H. Sun, D.G. Willis, and W.F. Marzluff. 1996. Efficient extraction and partial purification of the polyribosomal-associated stem-loop binding protein bound to the 3 ' end of histone mRNA. Biochemistry 35: 2146-2156.
Harlow E. and D. Lane. 1988. Storing and purifying antibodies. In Antibodies: A laboratory manual, pp. 283-318. Cold Spring Harbor Laboratory, Cold Spring Harbor, NY.

Harris, M.E., R. Böhni, M.H. Schneiderman, L. Ramamurthy, D. Schümperli, and W.F. Marzluff. 1991. Regulation of histone mRNA in the unperturbed cell cycle: Evidence suggesting control at two posttranscriptional steps. Mol. Cell. Biol. 11: $2416-2424$.

Heintz, N. 1991. The regulation of histone gene expression during the cell cycle. Biochim. Biophys. Acta Gene Struct. Expression 1088: 327-339.

Jackson, R.J. and N. Standart. 1990. Do the poly(A) tail and 3' untranslated region control mRNA translation? Cell 62: 1524.

Kalland, K.-H., A.M. Szilvay, K.A. Brokstad, W. Saetrevik, and G. Haukenes. 1994. The human immunodeficiency virus type 1 Rev protein shuttles between the cytoplasm and nuclear compartments. Mol. Cell. Biol. 14: 7436-7444.

McCombie, W.R., A. Martin-Gallardo, J.D. Gocayne, M. FitzGerald, M. Dubnick, J.M. Kelley, L. Castilla, L.I. Liu, S. Wallace, S. Trapp, et al. 1992. Expressed genes, Alu repeats and polymorphisms in cosmids sequenced from chromosome 4p16.3. Nature Genet. 1: 348-353.

Martin, F., A. Schaller, S. Egilte, D. Schümperli, and B. Muller. 1997. The gene for histone RNA hairpin-binding protein is located on human chromosome 4 and encodes a novel type of RNA-binding protein. $E M B O \%$. (in press).

Marzluff, W.F. and N.B. Pandey. 1988. Multiple levels of regulation of histone mRNA concentrations. Trends Biochem. Sci. 13: 49-52.

Melin, L., D. Soldati, R. Mital, A. Streit, and D. Schümperli. 1992. Biochemical demonstration of complex formation of histone pre-mRNA with U7 small nuclear ribonucleoprotein and hairpin binding factors. EMBO J. 11: 691-697.

Michael, W.M., M.Y. Choi, and G. Dreyfuss. 1995. A nuclear export signal in hnRNP Al: A signal-mediated, temperaturedependent nuclear protein export pathway. Cell 83: 415422.

Mowry, K.L. and J.A. Steitz. 1987a. Both conserved signals on mammalian histone pre-mRNAs associate with small nuclear ribonucleoproteins during $3^{\prime}$ end formation in vitro. Mol. Cell. Biol. 7: 1663-1672.

- $1987 \mathrm{~b}$. Identification of the human U7 snRNP as one of several factors involved in the $3^{\prime}$ end maturation of histone premessenger RNA's. Science 238: 1682-1687.

Mowry, K.L., R. Oh, and J.A. Steitz. 1989. Each of the conserved sequence elements flanking the cleavage site of mammalian histone pre-mRNAs has a distinct role in the 3 '-end processing reaction. Mol. Cell. Biol. 9: 3105-3108.

Nietfeld, W., H. Mentzel, and T. Pieler. 1990. The Xenopus laevis poly(A) binding protein is composed of multiple functionally independent RNA binding domains. EMBO $I$. 9: 3699-3705.

Pandey, N.B. and W.F. Marzluff. 1987. The stem-loop structure at the $3^{\prime}$ end of histone mRNA is necessary and sufficient for regulation of histone mRNA stability. Mol. Cell. Biol. 7: 4557-4559.

Pandey, N.B., J.-H. Sun, and W.F. Marzluff. 1991. Different complexes are formed on the $3^{\prime}$ end of histone mRNA in nuclear and polysomal extracts. Nucleic Acids Res. 19: 5653-5659.

Pandey, N.B., A.S. Williams, J.-H. Sun, V.D. Brown, U. Bond, and W.F. Marzluff. 1994. Point mutations in the stem-loop at the $3^{\prime}$ end of mouse histone mRNA reduce expression by reducing the efficiency of $3^{\prime}$ end formation. Mol. Cell. Biol. 14: 1709-1720.

Piñol-Roma, S. and G. Dreyfuss. 1992. Shuttling of pre-mRNA 
Wang et al.

binding proteins between nucleus and cytoplasm. Nature 355: 730-732.

Schümperli, D. 1986. Cell-cycle regulation of histone gene expression. Cell 45: 571-572.

SenGupta, D., B. Zhang, B. Kraemer, P. Prochart, S. Fields, and M. Wickens. 1996. A three-hybrid system to detect RNAprotein interactions in vivo. Proc. Natl. Acad. Sci. 93: 84968501.

Soldati, D. and D. Schümperli. 1988. Structural and functional characterization of mouse U7 small nuclear RNA active in 3 ' processing of histone pre-mRNA. Mol. Cell. Biol. 8: 15181524.

Stauber, C. and D. Schümperli. 1988. 3' processing of premRNA plays a major role in proliferation-dependent regulation of histone gene expression. Nucleic Acids Res. 16: 9399-9413.

Stauber, C., B. Lüscher, R. Eckner, E. Lotscher, and D. Schümperli. 1986. A signal regulating mouse histone $\mathrm{H} 4$ mRNA levels in a mammalian cell cycle mutant and sequences controlling RNA $3^{\prime}$ processing are both contained within the same 80-bp fragment. EMBO J. 5: 3297-3303.

Streit, A., T.W. Koning, D. Soldati, L. Melin, and D. Schümperli. 1993. Variable effects of the conserved RNA hairpin element upon $3^{\prime}$ end processing of histone pre-mRNA in vitro. $\mathrm{Nu}$ cleic Acids Res. 21: 1569-1575.

Sun, J.-H., D.R. Pilch, and W.F. Marzluff. 1992. The histone mRNA $3^{\prime}$ end is required for localization of histone mRNA to polyribosomes. Nucleic Acids Res. 20: 6057-6066.

Taylor, J.D., S.E. Wellman, and W.F. Marzluff. 1986. Sequences of four mouse histone $\mathrm{H} 3$ genes: Implications for evolution of mouse histone genes. J. Mol. Evol. 23: 242-249.

Vasserot, A.P., F.J. Schaufele, and M.L. Birnstiel. 1989. Conserved terminal hairpin sequences of histone mRNA precursors are not involved in duplex formation with the U7 RNA but act as a target site for a distinct processing factor. Proc. Natl. Acad. Sci. 86: 4345-4349.

Williams, A.S. and W.F. Marzluff. 1995. The sequence of the stem and flanking sequences at the $3^{\prime}$ end of histone mRNA are critical determinants for the binding of the stem-loop binding protein. Nucleic Acids Res. 23: 654-662.

Williams, A.S., T.C. Ingeldue, B.K. Kay, and W.F. Marzluff. 1994. Changes in the stem-loop at the $3^{\prime}$ terminus of histone mRNA affects its nucleocytoplasmic transport and cytoplasmic regulation. Nucleic Acids Res. 22: 4660-4666. 


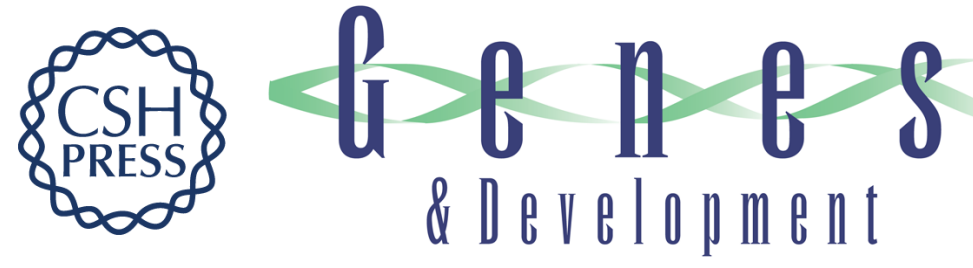

\section{The protein that binds the 3' end of histone mRNA: a novel RNA-binding protein required for histone pre-mRNA processing.}

Z F Wang, M L Whitfield, T C Ingledue, et al.

Genes Dev. 1996, 10:

Access the most recent version at doi:10.1101/gad.10.23.3028

References This article cites 37 articles, 15 of which can be accessed free at:

http://genesdev.cshlp.org/content/10/23/3028.full.html\#ref-list-1

License

Email Alerting

Service

Receive free email alerts when new articles cite this article - sign up in the box at the top right corner of the article or click here.

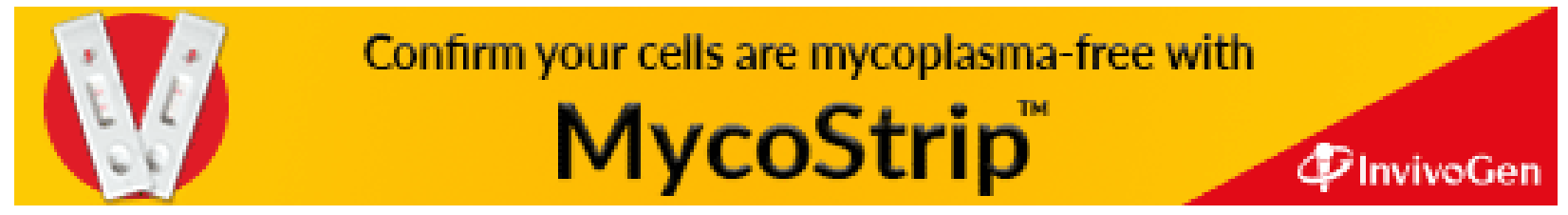

